\title{
The Effects of Cooperative Learning on Improving College Students' Reading Comprehension
}

\author{
Wenjing Zuo \\ Zhenjiang Watercraft College of PLA, Jiangsu, China \\ Email: Zuowj5945@yahoo.com.cn
}

\begin{abstract}
In cooperative learning students work with their peers to accomplish a shared goal through interdependence, interaction and team work among all group members rather than working alone. This article discusses three main methods of cooperative learning and how to implement cooperative learning in college English reading class. During the process some key elements should be taken into consideration, including classroom atmosphere, the design of tasks and the teacher's role.
\end{abstract}

Index Terms - cooperative learning, English reading, classroom activities

\section{INTRODUCTION}

One of the greatest challenges confronting English as a Foreign Language (EFL) learners is how to improve their reading comprehension achievement, which is actually the concern of both EFL learners and instructors. Recent years have witnessed a growing interest in investigating and introducing approaches such as Cooperative Learning (CL) into classroom teaching to help students improve their reading skills. In the traditional teacher-centered classroom, teachers dominate the whole class and are regarded as the unique authority, which limits the students' chances to participate in real communication in classroom. It is necessary to build an effective model of English teaching, changing this kind of teacher-centered form and facilitating the development of students' five skills of English. Though cooperative learning is widely studied and recommended by educators and researchers, for most of the teachers there are still a lot of difficulties in how to apply it in English class. Consequently, the purpose of the present study is to explore the feasibility of the application of CL in reading class teaching.

\section{WHAT IS COOPERATIVE LEARNING?}

CL dates from the early 1970s in America, and achieved substantial development in the middle of 1970s to 1980s. It is a method of instruction whereby students grouped in small learning teams work in cooperation with each other to solve a problem, or to perform a task presented by the teacher. In David and Roger Johnson's opinion (2001), Cooperative Learning is a successful teaching strategy in which small teams, each with students of different levels of ability, use a variety of learning activities to improve their understanding of a subject. Each member of a team is responsible not only for learning what is taught but also for helping teammates learn, thus creating an atmosphere of achievement. Students work on the assignment until all group members successfully understand and complete it. The Chinese scholar Wang Tan (2001) gave the following definition, "Cooperative Learning is a system of teaching strategy which promotes the students to cooperate in heterogeneous teams toward a common goal and are rewarded according to the success of the team."

From above, we can see CL shares the same idea that students work together and are responsible for their own as well as others' learning. Different from traditional group instruction, however, CL is much more than simply placing students in groups and telling them to work together. It is only when groups are structured so that students understand what they are expected to do and how they are expected to work together that the potential for cooperation and learning is maximized (Johnson \& Johnson, 1990). In fact, the following elements crucial to structured and effective cooperative learning, as described by Johnson and Johnson (1990) were included. They were: (a) task interdependence which was established in the groups so that each member had to contribute to the group task; (b) individual accountability was established so that all members understood they were required to report on their own contributions; (c) students actively promoted each other's learning; (d) students were trained in the interpersonal and small-group skills needed to facilitate group work. These skills included: actively listening to each other, providing constructive feedback to each other on suggestions and ideas; encouraging everyone to contribute to the group efforts; sharing tasks and resources fairly; trying to understand the other person's perspective; and, monitoring and evaluating the group's progress.

\section{THEORETICAL RELEVANCE AND EFFICACY OF COOPERATIVE LEARNING}


Research on the applications of cooperative learning suggest that learners working together acquire more language and social skills than their counterparts studying the same content under individualistic classroom conditions. As such, it accommodates the tenets of the theories of cognitive and social constructivism as proposed by Piaget and Vygotsky, respectively. It also maximizes opportunities for authentic and communicative language practice in a motivating, supportive, and stress-reduced environment. Finally, CL correlates to language acquisition theory in the domains of comprehensible input and output, $i+1$ discourse, low affective filter, bridging social language and academic language, and combining language and content learning.

Cooperative learning is beneficial for second language learners in a number of ways. Small group work enriches the language classroom with comprehensible, developmentally appropriate, redundant, and somewhat accurate input as described by Krashen (1988) as well as promoting frequent, communicative, and referential classroom talk in a supportive, motivating, and feedback-rich environment. Furthermore, Olsen and Kagan (1992) maintained that cooperative learning offers three major benefits relative to (a) providing a richness of alternatives to structure interaction among students, (b) addressing content area learning and language development needs within the same organizational framework, and (c) increasing opportunities for individualized instruction. McDonell (1992) argued that the cooperative classroom is well-suited for second language learners as it enables them to communicate, collaborate, problem-solve, and think critically.

\section{Methods Of COOPERATIVE LEARNING}

Essentially, cooperative learning includes a variety of strategies and structures that utilize students' collaboration to enhance learning and maximize interaction among students according to the key elements of CL put forward by Johnson and Johnson. Table 1 presents the various cooperative learning models, their history, developers and possible primary applications in the context of ESL/EFL instruction.

TABLE 1

MODERN METHODS OF COOPERATIVE LEARNING

\begin{tabular}{|l|l|l|l|}
\hline $\begin{array}{l}\text { Researcher } \\
\text { Developer }\end{array}$ & Date & Method & ESL/EFL Primary Applications \\
\hline Johnson \& Johnson & Mid 1970s & Learning Together & Reading, Writing, Speaking, Culture \\
\hline De Vries \& Edward & Early 1970s & Teams-Games-Tournaments (TGT) & Language Rules and Mechanics \\
\hline Sharan \& Sharan & Mid 1970s & Group Investigation (GI) & Writing, Culture \\
\hline $\begin{array}{l}\text { Aronson, Blaney, Sikes, } \\
\text { Stephan \& Snapp; Slavin }\end{array}$ & Late 1970s & Jigsaw Procedure & Reading, Literature \\
\hline Slavin & Late 1970s & $\begin{array}{l}\text { Student Teams-Achievement } \\
\text { Divisions (STAD) }\end{array}$ & Language Rules and Mechanics \\
\hline Cohen & Early 1980s & Complex Instruction (CI) & $\begin{array}{l}\text { Social Skills, Culture, Reading, Writing, } \\
\text { Language Rules and Mechanics }\end{array}$ \\
\hline Kagan & Mid 1980s & Cooperative learning Structures & Speaking, Listening, Reading, Writing \\
\hline $\begin{array}{l}\text { Stevens, Madden, Slavinn, \& } \\
\text { Farnish }\end{array}$ & Mid 1980s & $\begin{array}{l}\text { Curriculum Packages: Cooperative } \\
\text { Integrated Reading and } \\
\text { Composition (CIRC) }\end{array}$ & $\begin{array}{l}\text { Reading, Writing, Spelling, Vocabulary, } \\
\text { Literature }\end{array}$ \\
\hline
\end{tabular}

Out of the many methods that different teachers or researchers have developed, the following three have received the most attention from English teachers. The first cooperative form of learning is Student Team Achievement Divisions (STAD). According to Ghaith and Yaghi (1998), the STAD technique has consistently been shown to be among the most simple and effective CL methods in improving student achievement of well defined objectives in various subjects. Slavin (1978) asserts that STAD is a technique of CL which includes small heterogeneous teams of 4-6 members who tutor each other on the material in the course and prepare each other for weekly quizzes. To be more specific, students are assigned to four- to six-member learning teams that are mixed in performance level, sex, and ethnicity. The teacher presents a lesson, and then students work within their teams to make sure that all team members have mastered the lesson. Finally, all students take individual quizzes on the material, at which time they may not help one another. STAD operates on the principle that students work together to learn and are responsible for their teammates' learning as well as their own, and emphasizes having team goals that are dependent on the learning of all group members.

Jigsaw is another form of cooperative instruction. The jigsaw learning technique, first developed and implemented by Elliot Aronson in 1978, is a structured, cooperative strategy that avoids many of the problems of other forms of learning in a group. In the jigsaw classroom, the day's lesson is divided into several segments, and each student, who is in one of several jigsaw groups (of three to five students each), is assigned to learn about one segment of the written material. Before reporting on their topic to their jigsaw groups, students meet first with other students who have been assigned the same segment (one from each jigsaw group) in a temporary "expert" group. Together, the experts research their segment, discuss, and clear up questions with each other. Finally, the jigsaw groups reconvene, and each student in each group acts as a tutor to the group on his or her specialty topic. Group members must work together as a team to accomplish a common goal; each person depends on all the others. Group goals and individual goals complement and support each other.

The third model applicable to improving reading achievement is Learning Together (LT) developed by David 
Johnson and Roger Johnson at the University of Minnesota. It involves students working in four- or five-member heterogeneous groups on assignment sheets. The groups hand in a single sheet, and receive praise and rewards based on the group product. The method emphasizes teambuilding activities before students begin working together and regular discussions within groups about how well they are working together.

\section{COOPERATIVE LEARNING AND ENGLISH READING}

Studies have shown that cooperative learning provides better learning opportunities. It will increase language practice opportunities for participants, promote positive affective climate, and motivate learners. On the other hand, it is widely recognized that reading plays an important role in improving the comprehensive language competence in English learning and is regarded as the core and focus of English teaching. Therefore, English reading counts for a big proportion in English learning. Thus we should take cooperative learning into college English reading class. In teaching reading, great care should be taken regarding classroom atmosphere, the design of reading tasks and the skills involved, and the teacher's role.

First, it is quite necessary to create relaxing and harmonious classroom atmosphere. Relaxing and harmonious classroom atmosphere will result in high motivation and interest in learning English, which in turn will be beneficial to learners' achievement. In the traditional teacher-centered and competitive English classroom, the students are often ignored and always feel anxious and oppressive. Some researches show that under the pressure of peers' competition the learners are always more anxious and nervous than inferior to the students in the cooperative learning groups. However, harmonious and relaxing classroom atmosphere can provide students safety, warmth, empathy, help, genuineness and respect. In such an atmosphere, the affective filtering is weakened to a lower degree. Students are encouraged to perform in their own way without worrying about negative social evaluation, their anxiety is relieved, motivation internalized, and they are likely to participate in learning and encourage each other to achieve goals actively. Stevick (1988) believed that the classroom atmosphere a teacher cultivates greatly influences the motivation and attitudes of the learners.

In the second place, the selected texts and attached tasks should be carefully chosen and designed to develop the students' reading skills. Preferably, tasks should motivate student and should be designed to encourage selective and intelligent reading for the main meaning rather than test the students' understanding of trivial details. Also, tasks should help develop students' reading skills rather than test their reading comprehension. Generally speaking, teaching reading in the classroom is divided into three stages: pre-reading, while-reading, and post reading. In the pre-reading stage, some tasks should be assigned to the learning groups before class, which include previewing the text, looking up new words in the dictionary, or colleting relevant knowledge about the topic. Students are encouraged to find out difficult points in previewing the text on their own. Then discussion will be held on their findings within the group and group members should help and support each other during the process. In classroom teaching, the teacher should try to set the context or scene around the theme of the text, getting the students familiarized with the cultural and social background knowledge relevant to the reading text as well as the general knowledge about the world. Take Unit Six Christmas Spirit in Zooming In: An Integrated English Course (Book One) for example. The learning groups are required to collect and sort out related information on Christmas party and gathering, celebrations of Christmas and famous quotes about Christmas. When the class begins, one representative from each group is asked to give a report on their colleted data. After that, the teacher will explain some words which will make it difficult for the students' comprehension of the text and leave some for them to guess in reading. Then students scan the text and make predictions based on the title, illustrations, new words, True or False questions, and so on. Finally, the teacher asks each group to express their views on the following question: What is the real spirit of Christmas and how Christmas spirit touched the hearts of those concerned? Through these cooperative activities, the teacher aims at arousing the enthusiasm of the students and developing their ability of colleting and sorting out information as well as their team spirit in collaborative work. In the while-reading stage, the teacher should help the students get familiar with the content and structure of the text by skimming and scanning. The group members will guess the meaning of some new words and expressions in the text and each group will report their answers in class. Then they read the text carefully and are encouraged to raise questions based on their understanding of the text. In the post reading part, the design of tasks should provide the students with opportunities to relate what they have read to what they already know or what they feel. In addition the tasks should enable students to produce language based on what they have learned. The group members may discuss the topic sentence for each part and the main idea of the text and summarize their understanding of the "Christmas Spirit". Then the teacher may help them analyze the organization of the type of the text and the writing style. Discussion, role-play, gap-filling, retelling, false summary, and writing are recommended activities to provide an effective platform for cooperative learning after class and strengthen what they have learned in class.

Thirdly, the teacher plays an important role in class. Teachers should help the students not merely to cope with one particular text in front of them but with their reading strategies and reading ability in general. We should encourage them to use reading strategies which will enable them to tackle any further texts. Teachers should also help students to read on their own. We should aim at gradually withdrawing our guidance as our students are making progress so that they eventually become independent readers. These principles require teachers attach great importance to student-centeredness in class, which is just an advantage of cooperative learning. In cooperative learning, peers are both 
"tutor" and "tutee", who provide the kind of support that is usually provided by the teacher. The teacher in group activities is free to listen and assess individual student learning, facilitating student interaction and offering individual help, and taking note of general problems to address to the class. It is also possible in these groups to adapt the tasks both in terms of the content, the level and the type of reporting required for individual students. The teacher provides the chance for reading, the materials students will need, and guidance and support throughout the process. The teacher should design more cooperative learning activities and make students understand that cooperation with peers will help them improve academic achievement effectively. As Johnson and Johnson said, "to great extent, learning efficiency will be increased a lot when each individual student offers task-related help and support reciprocally." Under the friendly and cooperative situation, the students can get more help, warmth, trust, respect, and support from peers.

\section{CONCLUSION}

In conclusion, it is feasible and effective to implement CL into reading classes. First, this student-centered approach changes the one-way operation in traditional classroom and creates harmonious atmosphere by establishing active cooperation among students. It provides EFL learners with opportunities to acquire a foreign language through group interaction and discussion where their stress will be reduced by working in small groups. Therefore, fear will be lower and their motivation to learn will be enhanced greatly. The change from passive reception into active cooperation and exploration arouses their interest and involvement in classroom activities. However, in order to bring this new approach into full play in teaching English, teachers should further make theoretical and empirical studies and make great effort in designing more suitable and effective classroom activities so as to improve their reading competence as well as their language skills.

\section{REFERENCES}

[1] Johnson, D. W. \& Johnson, R. T. (1990). Social Skills for Successful Group Work. Educational Leadership. 47 (4), 29-33.

[2] Johnson, D. W. \& Johnson, R. T. (2001). (Eds.) Cooperative Learning. MN: Interaction Book Company.

[3] Kagan, S. (1996). We can talk--cooperative learning in the elementary ESL classroom. Newsletter English as a Foreign Language 16 (Serial No. 1 and 2).

[4] Krashen, S.D. (1988). Second Language Acquisition and Second Language Learning. Prentice Hall, Englewood Cliffs, NJ.

[5] McDonell, W. (1992). Language and cognitive development through cooperative group work. In: Kessler, C. (Ed.). Cooperative Language Learning a Teacher's Resource Book. Prentice Hall Regents, Englewood Cliffs, NJ, 51-64.

[6] Olsen, R., Kagan, S. (1992). About cooperative learning. In: Kessler, C. (Ed.). Cooperative Language Learning a Teacher's Resource Book. Prentice Hall Regents, Englewood Cliffs, NJ, 1-30.

[7] Shaaban, K., Ghaith, G. (2005). The theoretical relevance and efficacy of using cooperative learning in the ESL/EFL classroom. TESL Reporter 38, 2, (2005), pp. 14-28

[8] Slavin, R. (1978). Student teams and achievement divisions. Journal of Research and Development in Education, $12,39-49$.

[9] Wang, T. (2001). (Ed.) Cooperative Learning—Theory and Strategy. Beijing: Xueyuan Publishing House.

Wenjing Zuo was born in Yangzhong, Jiangsu, China in 1979. She received her M.A. degree in linguistics from Nanjing University, China in 2008.

She is currently a lecturer in the Foreign Languages Department, Zhenjiang Watercraft College of PLA, Zhenjiang, China. Her research interests include applied linguistics and language teaching. 